\title{
Increased carotid IMT in overweight and obese women affected by Hashimoto's thyroiditis: an adiposity and autoimmune linkage?
}

\author{
Marco M Ciccone ${ }^{1 *}$, Giovanni De Pergola ${ }^{2}$, Maria T Porcelli ${ }^{3}$, Pietro Scicchitano ${ }^{1}$, Pasquale Caldarola ${ }^{3}$, \\ Massimo lacoviello ${ }^{1}$, Guida Pietro ${ }^{1}$, Francesco Giorgino ${ }^{2}$, Stefano Favale ${ }^{1}$
}

\begin{abstract}
Background: Hashimoto's thyroiditis is the most important cause of hypothyroidism. It is a systemic disease that can even affect the cardiovascular system, by accelerating the atherosclerotic process. Aim of this study was to examine whether autoimmune thyroiditis has an effect on the intima-media thickness of the common carotid artery (IMT-CCT), independently of the thyroid function and well-known cardiovascular risk factors. Hashimoto's thyroiditis is a systemic disease. The aim is to examine whether autoimmune thyroiditis and adiposity can effect carotid IMT independently of thyroid hormones and cardiovascular risk factors.

Methods: A total of 104 obese women (BMI $\geq 25.0 \mathrm{~kg} / \mathrm{m}^{-2}$ ), with FT3 and FT4 serum levels in the normal range and TSH levels $<4.5 \mu \mathrm{U} / \mathrm{ml}$, were investigated. None of these patients was taking any kind of drug influencing thyroid function. Measurements were made of the IMT-CCT, BMI, waist circumference, blood pressure levels, as well as fasting TSH, FT3, FT4, anti-thyroid antibodies, insulin, fasting glycemia, triglycerides, total and HDL-cholesterol serum concentrations.
\end{abstract}

Results: Of the 104 women, 30 (28.8\%) were affected by autoimmune thyroiditis. Significantly higher values of IMTCCT $(p<0.05)$, TSH $(p<0.05)$, and triglycerides $(p<0.05)$ were obtained, and significantly lower values of FT4 $(p<$ 0.05), in patients with Hashimoto's thyroiditis as compared to those with a normal thyroid function. When examining the whole group together, at multiple regression analysis Hashimoto's thyroiditis maintained a positive association with the IMT $(p<0.001)$, independently of age, hypertension, BMI, and the fasting serum levels of TSH, FT3, FT4, insulin, fasting glycemia, triglycerides, total and HDL-cholesterol levels.

Conclusions: The present study shows that Hashimoto's thyroiditis is associated to an increased IMT only in overweight and obese, independently of the thyroid function, BMI and cardiovascular risk factors. These results suggest that Hashimoto's thyroiditis is a marker of evolution of the atherosclerosis if combined to adiposity.

\section{Background}

Although published data [1-3] clearly indicate that there is a close relationship between even sub-clinical thyroid dysfunction and an increased cardiovascular risk, the underlying pathogenic process is still unknown. Researchers have so far concentrated on demonstrating the existence of the correlation and evaluating the extent to which different degrees of thyroid dysfunction increase the risk [4-6], but the study populations have

\footnotetext{
* Correspondence: ciccone@cardio.uniba.it

${ }^{1}$ Section of Cardiovascular Disease, Department of Emergency and Organ

Transplantation, University of Bari, School of Medicine, Bari, Italy
}

rarely been subdivided on the basis of the type of thyroid disease. We believe that this second approach could highlight the close relationships between the two organs, allowing us to study the natural pathogenic mechanisms underlying the impact of thyroid dysfunction on cardiovascular risk, rather than the effects of the secreted hormones on the cardiovascular system in general [7].

Aim of this study was therefore to investigate whether autoimmune Hashimoto's thyroiditis increases the intima-media thickness of the common carotid artery (IMT-CCA), regardless of thyroid dysfunction or traditional cardiovascular risk factors. 


\section{Methods \\ Subjects}

A total of 104 overweight or obese women (BMI $\geq 25.0$ $\mathrm{kg} / \mathrm{m}^{2}$ ) attending the Obesity Clinic of the Institute of Internal Medicine, Endocrinology and Metabolic Disease, and the Emergency and Organ Transplant Department of Bari University General Hospital, were enrolled in the study, inclusion criteria being normal blood FT3 and FT4 concentrations, and TSH levels of $<4.5 \mu \mathrm{U} / \mathrm{ml}$.

Exclusion criteria were smoking habit, thyroid or other known endocrine diseases, cardiovascular diseases (coronary heart disease, arrhythmia, heart failure), vascular brain diseases (stroke or a transient ischemic attack), peripheral obstructive artery disease (claudicatio intermittens, delayed or absent peripheral pulses), documented diabetes mellitus, a family or personal history of severe dyslipidemia (triglyceride or total cholesterol levels of $>300 \mathrm{mg} / \mathrm{dl}$ ), chronic liver disease, known kidney disease or any other chronic severe disease. Women taking any kind of medication other than anti-hypertensive drugs, including $\beta$-blockers, were also excluded.

Of the 104 enrolled subjects, 30 had Hashimoto's thyroiditis (serum anti-thyroglobulin [Tg-Ab] and antithyroid peroxidase antibodies [TPO-Ab]; the remaining 74 did not have positive serum auto-antibodies and were therefore considered free of autoimmune thyroiditis: these were taken as the controls. All patients had serum fasting glucose levels of $<126 \mathrm{mg} / \mathrm{dl}$.

High blood pressure was present in $30 \%$ of the women with, and $31 \%$ of those without autoimmune thyroiditis. Arterial hypertension was diagnosed on the basis of preexisting treatment with antihypertensive drugs or the criteria of the Third Report of the National Cholesterol Education Program (NCEP) Expert Panel on Detection, Evaluation, and Treatment of High Blood Cholesterol in Adults (Adult Treatment Panel III) Final Report [8]: i.e. systolic (SBP) and diastolic blood pressure (DBP) levels of $\geq 130$ and $\geq 85 \mathrm{mmHg}$. Blood pressure was evaluated using a mercury sphygmomanometer with an appropriate-sized cuff with the patients in sitting position, and the average of three measurements was recorded.

Patients were instructed not to change their dietary habits or practice more sport during the study period.

All patients and controls underwent to an ultrasound assessment of their thyroid morphologies.

The study was approved by the Institutional Review Board of Bari University General Hospital and carried out in accordance with the principles of the Helsinki Declaration; all patients gave informed consent before entering the study.

\section{Anthropometric evaluations}

The following anthropometric parameters were evaluated: weight $(\mathrm{kg})$, height $(\mathrm{cm})$, body mass index (BMI) expressed as weight in kilograms divided by the square of height in metres (normal $<24.9 \mathrm{~kg} / \mathrm{m}^{2}$; overweight $25-29.9 \mathrm{~kg} / \mathrm{m}^{2}$; obese $\geq 30 \mathrm{~kg} / \mathrm{m}^{2}$ ), and waist circumference $(\mathrm{cm})$.

\section{Biochemistry analyses}

Blood samples were taken fasting at 8.00 a.m., and used to measure fasting glycemia $(\mathrm{mg} / \mathrm{dl})$, serum insulin $(\mu \mathrm{UI} / \mathrm{ml}$; normal values [n.v.] 4.3-19.9 $\mu \mathrm{U} / \mathrm{ml})$, FT3 (pg/ ml; n.v. 2.2-4.2 pg/ml), FT4 (pg/ml; n.v. 8.1-17.1 pg/ml), TSH $(\mu \mathrm{UI} / \mathrm{ml}$; n.v. $0.3-3.6 \mu \mathrm{U} / \mathrm{ml})$, total cholesterol (mg/dl), HDL cholesterol $(\mathrm{mg} / \mathrm{dl})$, triglycerides $(\mathrm{mg} / \mathrm{dl})$, Tg-Ab (UI/ml; n.v. < $50 \mathrm{UI} / \mathrm{ml})$ and TPO-Ab (UI/ml; n.v. $<10 \mathrm{UI} / \mathrm{ml})$. Blood glucose was measured using the glucose-oxidase method (Sclavo, Siena, Italy); serum insulin by radio-immune assay (Behring, Scoppito, Italy); FT3, FT4 and TSH using a competitive photometric method based on the solid phase antigen-linked technique (LIASON FT3, LIASON FT4, LIASON TSH, DiaSorin, Saluggi, Italy); total and HDL cholesterol, and triglyceride levels using an enzymatic method (Boehringer Mannheim, Diagnostica Mannheim, Mannheim, Germany); auto-antibodies by radio-immune assays (TgAb IRMA, Biocode, Sclessin, Belgium; TPO-Ab RIA, Sorin Biomedica, Saluggia, Italy).

\section{IMT-CCA ultrasonography}

All patients underwent a two-dimensional echo-colour Doppler examination of the carotid arteries using a high-definition vascular echograph (Philips Sonos 5500 Ultrasound Scanner) and a 7.5 MHz linear electronic probe. They were placed in supine position with their neck in extension and rolled contralaterally by about $45^{\circ}$. The common carotid arteries were examined in the long axis view using a lateral projection and $2.5 \times$ image enlargement; bulbar dilation was considered to identify the border between the distal common carotid artery and carotid bulb [9-13]. None of the patients had atherosclerotic plaques, localised lesions $\geq 2 \mathrm{~mm}$ thick, or stenoses.

The images were focused on the intima-media complex of the arterial wall, frozen, and recorded on a videotape. IMT was measured using a digital device (Hewlett Packard, Borthell, Washington) according to Pignoli [9]: i.e. the distance between the principal border of one echogenic line and the principal border of a second, separated by a relatively hypoechoic space ("the double line pattern"). Three measurements were made 1 $\mathrm{cm}$ proximally from the carotid bulb on each side, and the average of the six measurements was recorded. Each scan was made by the same investigator, who was blinded to the patients' clinical history and characteristics. 


\section{Statistical analyses}

The data are expressed as mean values \pm standard deviation except for the category-specific variables, which are expressed in percentages. Between-group differences were analysed using Student's test for independent samples; frequencies were compared using the chi-squared exact test. The correlations between parameters were analysed using Pearson's linear correlation coefficient. The determinants of the independent IMTCCA variable were assessed by multiple regression analysis. All the analyses were made using STATISTICA 6.1 for Windows software (StatSoft Inc., Tulsa, OK, USA), and $p$ values of $<0.05$ were considered statistically significant.

\section{Results}

Table 1 shows the anthropometric, biochemical and IMT data on the population. There were no significant between-group differences as to demographic and anthropometric variables, but the patients with Hashimoto's thyroiditis had significantly higher IMT (Fig. 1; Panel A), TSH (Fig. 1; Panel B) and triglyceride levels, and significantly lower FT3 levels than the controls.
Subclinical hypothyroidism (normal serum concentrations of FT3 and FT4, and THS $\geq 3.6 \mu \mathrm{UI} / \mathrm{ml}$ ) was detected in three of the 74 patients without autoimmune thyroiditis (4.05\%) and seven of the 30 patients with Hashimoto' thyroiditis (23.3\%).

Table 2 shows Pearson's linear correlation coefficients for simple regression analysis of the IMT with the other parameters in the two groups and in the population as a whole. In the population as a whole, IMT was significantly and positively correlated with age, waist circumference, fasting glycemia, total cholesterol, triglycerides and hypertension; in the thyroiditis group, it was correlated with age (Fig. 2; Panel A), fasting glycemia (Fig. 2; Panel B), total cholesterol and triglycerides.

Table 3 shows the multiple regression analysis coefficients for the population as a whole, with the IMT as the dependent variable and Hashimoto's thyroiditis, age, BMI (Model 1) or waist circumference (Model 2), fasting glycemia, fasting insulin, FT3, FT4, TSH, total cholesterol, HDL-cholesterol, triglycerides and hypertension as independent variables. The two models showed a good fit $\left(R^{2}=0.41, P<0.001\right.$ in each case $)$ and the IMT-CCA retained its independent and positive association with age and the reference group (Hashimoto

Table 1 Characteristics of the studied population

\begin{tabular}{|c|c|c|c|c|}
\hline Variables & $n=104$ & HASHIMOTO $(n=30)$ & CONTROLS $(n=74)$ & $P$ \\
\hline Age (years) & $\begin{array}{c}39.8 \pm 11.1 \\
(18-66)\end{array}$ & $\begin{array}{c}41.1 \pm 11.9 \\
(21-66)\end{array}$ & $\begin{array}{c}39.2 \pm 10.8 \\
(18-61)\end{array}$ & 0.421 \\
\hline$B M I\left(\mathrm{~kg} / \mathrm{m}^{2}\right)$ & $\begin{array}{c}34.7 \pm 6 \\
(25-64.6)\end{array}$ & $\begin{array}{c}34.5 \pm 4.6 \\
(27.2-45.1)\end{array}$ & $\begin{array}{l}34.8 \pm 6.5 \\
(25-64.6)\end{array}$ & 0.847 \\
\hline Waist circumference $(\mathrm{cm})$ & $\begin{array}{c}105.9 \pm 12.8 \\
(82-155)\end{array}$ & $\begin{array}{c}105.6 \pm 10.3 \\
(88-132)\end{array}$ & $\begin{array}{l}106 \pm 13.7 \\
(82-155)\end{array}$ & 0.903 \\
\hline Fasting glycemia (mg/dl) & $\begin{array}{l}92 \pm 10.1 \\
(70-118)\end{array}$ & $\begin{array}{l}90.2 \pm 9.5 \\
(70-109)\end{array}$ & $\begin{array}{c}92.7 \pm 10.3 \\
(70-118)\end{array}$ & 0.253 \\
\hline Fasting insulinemia $(\mu \mathrm{IU} / \mathrm{ml})$ & $\begin{array}{c}28.4 \pm 17.9 \\
(5-99)\end{array}$ & $\begin{array}{c}29.5 \pm 16.8 \\
(6-72)\end{array}$ & $\begin{array}{c}28 \pm 18.4 \\
(5-99)\end{array}$ & 0.688 \\
\hline$T S H(\mu U / m l)$ & $\begin{array}{l}1.96 \pm 1.05 \\
(0.38-4.5)\end{array}$ & $\begin{array}{r}2.47 \pm 1.17 \\
(0.5-4.31)\end{array}$ & $\begin{array}{l}1.76 \pm 0.94 \\
(0.38-4.5)\end{array}$ & 0.002 \\
\hline FT3 $(p g / m l)$ & $\begin{array}{c}3.25 \pm 0.38 \\
(2.3-4)\end{array}$ & $\begin{array}{c}3.11 \pm 0.4 \\
(2.37-3.94)\end{array}$ & $\begin{array}{c}3.31 \pm 0.36 \\
(2.3-4)\end{array}$ & 0.015 \\
\hline FT4 $(p g / m l)$ & $\begin{array}{c}10.29 \pm 1.2 \\
(8-14.1)\end{array}$ & $\begin{array}{l}10.26 \pm 1.26 \\
(8.44-13.3)\end{array}$ & $\begin{array}{c}10.3 \pm 1.19 \\
(8-14.1)\end{array}$ & 0.869 \\
\hline Total cholesterol (mg/dL) & $\begin{array}{c}194.8 \pm 38.3 \\
(133-297)\end{array}$ & $\begin{array}{l}201 \pm 43.3 \\
(133-297)\end{array}$ & $\begin{array}{c}192.3 \pm 36.1 \\
(134-297)\end{array}$ & 0.299 \\
\hline HDL cholesterol (mg/dL) & $\begin{array}{c}49.1 \pm 10.7 \\
(25-85)\end{array}$ & $\begin{array}{l}49 \pm 9.7 \\
(31-77)\end{array}$ & $\begin{array}{c}49.1 \pm 11.1 \\
(25-85)\end{array}$ & 0.985 \\
\hline Triglycerides (mg/dL) & $\begin{array}{c}94.7 \pm 43.1 \\
(27-248)\end{array}$ & $\begin{array}{c}114.4 \pm 47.4 \\
(47-248)\end{array}$ & $\begin{array}{c}86.7 \pm 38.8 \\
(27-225)\end{array}$ & 0.003 \\
\hline IMT $(\mathrm{mm})$ & $\begin{array}{c}0.65 \pm 0.11 \\
(0.42-0.89)\end{array}$ & $\begin{array}{c}0.69 \pm 0.1 \\
(0.48-0.89)\end{array}$ & $\begin{array}{c}0.64 \pm 0.11 \\
(0.42-0.89)\end{array}$ & 0.026 \\
\hline Systolic blood pressure $(\mathrm{mmHg})$ & $\begin{array}{c}121.7 \pm 13.2 \\
(90-160)\end{array}$ & $\begin{array}{c}120.6 \pm 12.1 \\
(105-150)\end{array}$ & $\begin{array}{c}122.2 \pm 13.7 \\
(90-160)\end{array}$ & 0.573 \\
\hline Diastolic blood pressure $(\mathrm{mmHg})$ & $\begin{array}{c}79.0 \pm 8.6 \\
(65-110)\end{array}$ & $\begin{array}{c}76.8 \pm 6.9 \\
(65-90)\end{array}$ & $\begin{array}{c}79.8 \pm 9.14 \\
(65-110)\end{array}$ & 0.098 \\
\hline Hypertension (\%) & 30.8 & 30 & 31.1 & 0.915 \\
\hline
\end{tabular}

Mean values \pm Standard Deviation (Range) 

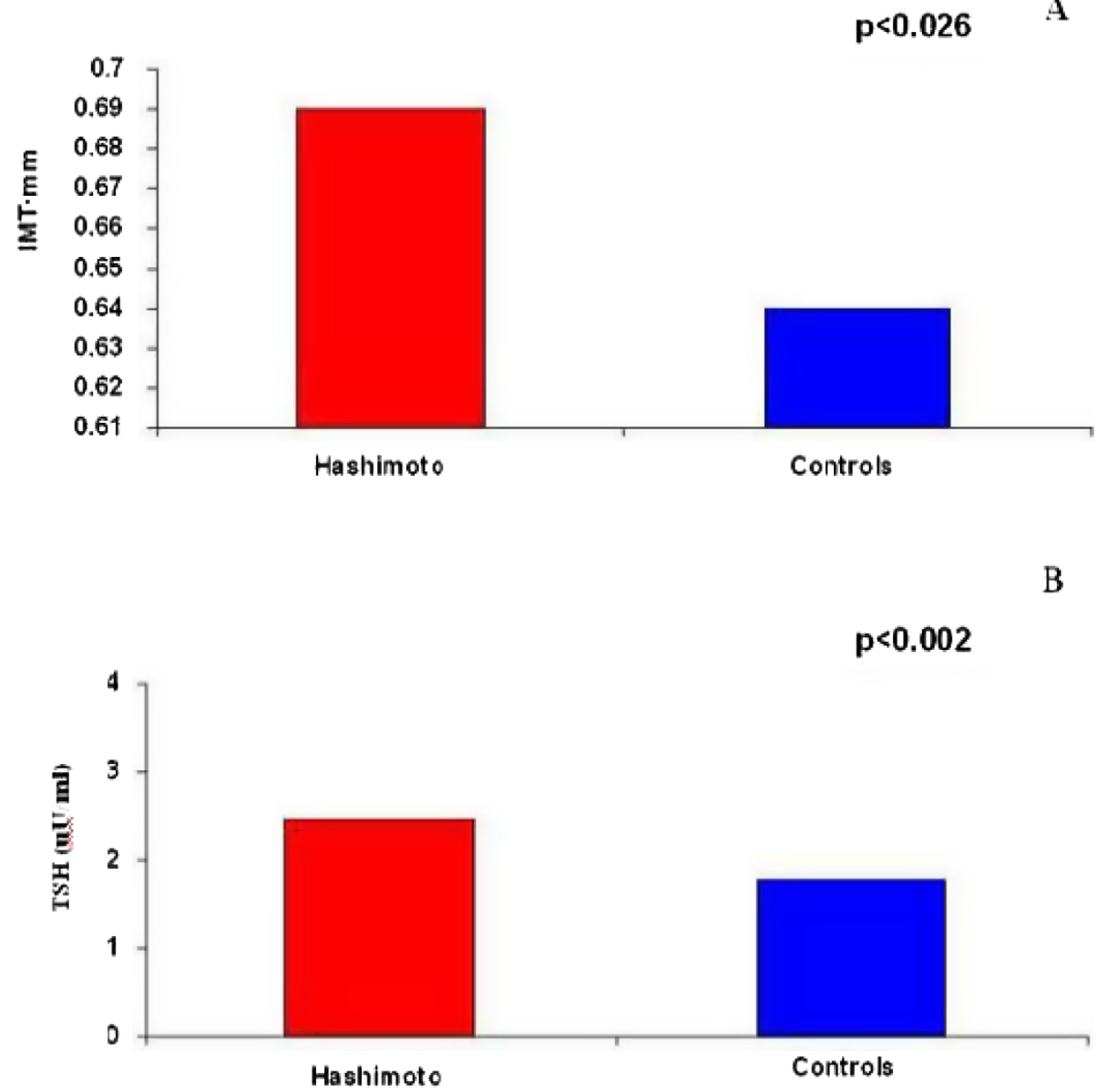

Figure 1 Panel A: IMT values in Hashimoto patients and controls; Panel B: TSH values in Hashimoto patients and controls.

thyroiditis $v s$ controls). The explanatory contribution of the other variables was not significant. Moreover, including in the analysis a dichotomic variables to take in account the presence of TSH lower than 3.5, age and Hashimoto remain positively associated with IMT in model 1 (respectively, $\mathrm{p}<0.001$ and $\mathrm{p}=0.048$ ) and model 2 (respectively, $\mathrm{p}<0.001$ and $\mathrm{p}=0.049$ ).

\section{Discussion}

Hashimoto's thyroiditis is one of the most popular thyroid disease. The diagnosis of Hashimoto's thyroiditis was defined on the basis of the presence of high serum thyroid peroxidase antibody concentrations and of the ultrasound examination, showing a hypoechogenic thyroid. Serum thyroid peroxidase antibodies were considered high whether their concentrations were higher than $40 \mathrm{UI} / \mathrm{ml}$, and they were high in 100 percent of patients with Hashimoto's thyroiditis. Moreover, serum thyroglobulin antibodies were considered high whether their concentrations were higher than $125 \mathrm{UI} / \mathrm{ml}$, and these antibodies were high in less than 50 percent of the patients.
Just the hypoechogenic aspect of thyroid on ultrasound examination let us having a good instrumental parameter in order to detect all patients affected by Hashimoto's thyroiditis

The importance of this study is that Hashimoto' thyroiditis per se increases the intima-media thickness of the common carotid artery regardless of thyroid function. Actually, Stamatelopoulos et al. [14] just underlined the positive effects of Hashimoto's thyroiditis on arterial stiffness, regardless the intima-madia thickness. But only overweight and obese women were enrolled in our study and the differences in study group may partly explain the different results between the Stamatelopoulos and our study.

All of the subjects we included in our study had normal serum FT3 and FT4 levels and, although patients with subclinical hypothyroidism were also included, there was no linear correlation between IMT and serum TSH levels. The correlation between IMT and Hashimoto thyroiditis is therefore independent of TSH and thyroid hormone values. 
Table 2 Pearson's correlation coefficients for simple linear regression between the IMT and all the other parameters in the Hashimoto patients, controls and the population as a whole

\begin{tabular}{|c|c|c|c|}
\hline & $\begin{array}{c}\text { Hashimoto } \\
(n=30)\end{array}$ & $\begin{array}{l}\text { Controls } \\
(n=74)\end{array}$ & $\begin{array}{c}\text { Total } \\
(n=104)\end{array}$ \\
\hline Age & $\begin{array}{c}0.60 * * * \\
p<0.001\end{array}$ & $\begin{array}{c}0.50^{* * *} \\
p<0.001\end{array}$ & $\begin{array}{c}0.53 \text { *** } \\
p<0.001\end{array}$ \\
\hline$B M I$ & $\begin{array}{c}-0.10 \\
p=0.613\end{array}$ & $\begin{array}{c}0.10 \\
p=0.382\end{array}$ & $\begin{array}{c}0.06 \\
p=0.572\end{array}$ \\
\hline Waist circumference & $\begin{array}{c}0.20 \\
p=0.294\end{array}$ & $\begin{array}{c}0.22 \\
p=0.062\end{array}$ & $\begin{array}{c}0.21^{*} \\
p=0.037\end{array}$ \\
\hline Fasting glycemia & $\begin{array}{c}0.62 * * * \\
p<0.001\end{array}$ & $\begin{array}{c}0.25^{*} \\
p=0.030\end{array}$ & $\begin{array}{c}0.311^{* *} \\
p=0.001\end{array}$ \\
\hline Fasting insulinemia & $\begin{array}{c}-0.08 \\
p=0.660\end{array}$ & $\begin{array}{c}0.05 \\
p=0.649\end{array}$ & $\begin{array}{c}0.03 \\
p=0.779\end{array}$ \\
\hline TSH & $\begin{array}{c}0.13 \\
p=0.481\end{array}$ & $\begin{array}{c}-0.05 \\
p=0.693\end{array}$ & $\begin{array}{c}0.08 \\
p=0.445\end{array}$ \\
\hline FT3 & $\begin{array}{c}-0.01 \\
p=0.951\end{array}$ & $\begin{array}{c}0.02 \\
p=0.841\end{array}$ & $\begin{array}{c}-0.04 \\
p=0.694\end{array}$ \\
\hline FT4 & $\begin{array}{c}0.03 \\
p=0.876\end{array}$ & $\begin{array}{c}-0.01 \\
p=0.941\end{array}$ & $\begin{array}{c}0 \\
p=0.987\end{array}$ \\
\hline Total cholesterol & $\begin{array}{c}0.46^{*} \\
p=0.011\end{array}$ & $\begin{array}{c}0.26^{*} \\
p=0.025\end{array}$ & $\begin{array}{c}0.33^{* *} \\
p=0.001\end{array}$ \\
\hline HDL cholesterol & $\begin{array}{c}0.00 \\
p=0.989\end{array}$ & $\begin{array}{c}-0.07 \\
p=0.570\end{array}$ & $\begin{array}{c}-0.05 \\
p=0.618\end{array}$ \\
\hline Triglycerides & $\begin{array}{c}0.52^{* *} \\
p=0.003\end{array}$ & $\begin{array}{c}0.23 \\
p=0.051\end{array}$ & $\begin{array}{c}0.36^{* * *} \\
p<0.001\end{array}$ \\
\hline Systolic blood pressure & $\begin{array}{c}0.48^{* *} \\
P=0.008\end{array}$ & $\begin{array}{c}0.34^{* *} \\
P=0.003\end{array}$ & $\begin{array}{c}0.35^{* * *} \\
P<0.001\end{array}$ \\
\hline Diastolic blood pressure & $\begin{array}{c}0.21 \\
P=0.270\end{array}$ & $\begin{array}{c}0.23^{*} \\
P=0.046\end{array}$ & $\begin{array}{c}0.18 \\
P=0.064\end{array}$ \\
\hline Hypertension & $\begin{array}{c}0.23 \\
p=0.231\end{array}$ & $\begin{array}{c}0.28 * \\
p=0.016\end{array}$ & $\begin{array}{c}0.26^{* *} \\
p=0.009\end{array}$ \\
\hline
\end{tabular}

$* \mathrm{P}<0.05 * * * \mathrm{P}<0.01 * * * * \mathrm{P}<0.001$

As smoking, diabetes mellitus and severe or familial hyperlipidemia were exclusion criteria [15], and the other atherogenic factors such as abdominal obesity, hypertension, fasting glycemia and insulin levels, and lipidemia typifying the study population did not influence the association between auto-immune thyroiditis and IMT, it can be said that Hashimoto's thyroiditis seems to be an independent cardiovascular risk factor. If this is true, all patients with Hashimoto's thyroiditis (including euthyroid patients) may benefit from L-thyroxin. Besides, Monzani et al. have clearly shown that six months of thyroid-replacement therapy in patients with hypothyroidism are sufficient to reduce carotid intimamedia thickness [16,17].

The pathogenetic mechanism underlying the increased IMT is not clear, but some hypotheses can be made [18-21]:

1) Although Hashimoto's thyroiditis is related to the IMT regardless of TSH and thyroid hormone levels, we found that our patients with thyroiditis had higher mean serum TSH and triglyceride levels, and lower mean blood FT3 concentrations than the controls. Furthermore, although only a minority of the enrolled women suffered from subclinical hypothyroidism, the percentage was higher among those with auto-immune thyroiditis (23.3\% vs $4.05 \%)$. For this reason, a first hypothesis is that Hashimoto thyroiditis, by reducing the thyroid function, is per se responsible for increasing the IMT even in subjects with normal FT3 and FT4 levels.

2) As expected, the IMT was directly correlated with age, waist circumference, hypertension, fasting glycemia, and total cholesterol and triglyceride levels, thus confirming the findings of previously published studies [21-23]. The correlation between the IMT and fasting glycemia is particularly interesting because none of the patients had fasting glycemia levels of $>110 \mathrm{mg} / \mathrm{dl}$, which suggests a second hypothesis, namely that defective glucose homeostasis may also be per se a cardiovascular risk factor in non-diabetic subjects [24-27].

We did not find a significant association between the IMT and fasting insulin levels, although high insulin concentrations are considered a surrogate marker of insulin resistance [15]. However, this is in line with the findings of previous studies that have not demonstrated a clear relationship between insulin concentrations and the angiographically-assessed severity of coronary disease $[28,29]$. Nevertheless, it is possible that determining fasting insulin concentrations by means of an immuno-assay is only an indirect measure of insulin resistance and cannot be compared with measures of in vivo hormone sensitivity indicating an independent association between insulin resistance and the IMT-CCA.

3) Finally, Hashimoto's thyroiditis is an autoimmune disease, and it is well-known that a number of auto-immune diseases are associated with arteritis, accelerated atherosclerosis progression and an increased cardiovascular risk (rheumatoid arthritis, systemic lupus erythematosus, antiphospholipid antibody syndrome...) [30], and so it cannot be excluded that Hashimoto's thyroiditis may in itself be responsible for auto-immune or inflammation-based arteritis. We have no firm evidence supporting such a hypothesis, but it could be an interesting issue to be addressed in future research. Such a consideration come from even from Taddei and al. study [7] in which they demonstrate the endothelial dysfunction coming from Hashimoto's thyroiditis, independently from others cardiovascular risk factors and rather associated with the autoimmune process by itself. For this reason Taddei et al. pointed out the beneficial use of anti-inflammatory drugs in reducing 


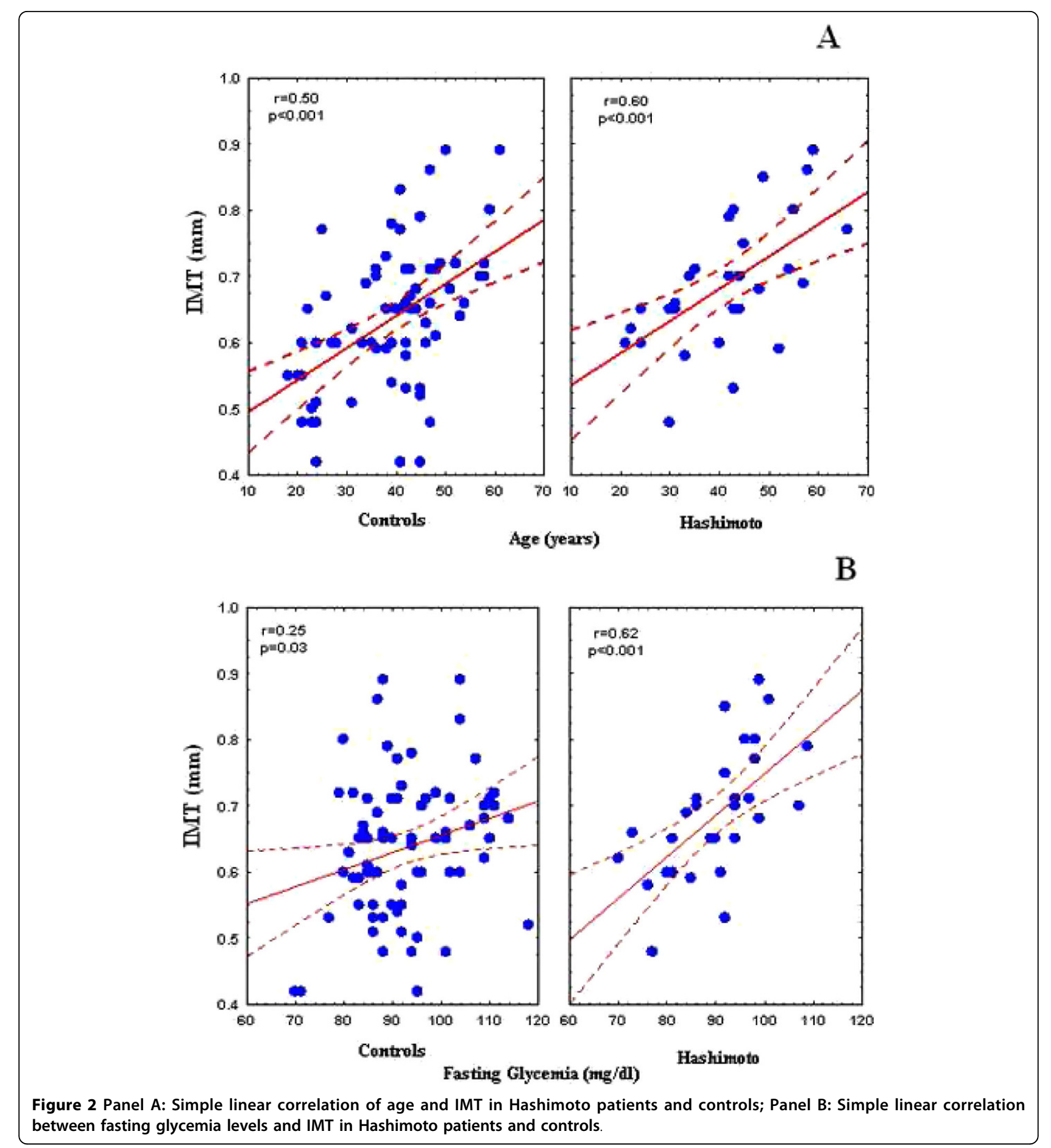

impaired endothelial function in patients with such a disease.

4) Besides, even though TSH levels were higher in the group with Hashimoto's thyroiditis, BMI and waist circumference were not different between thyroiditis and control groups, thus possibly excluding that higher TSH in the thyroiditis group is due to obesity itself.

\section{Conclusions}

In conclusion, our findings show that Hashimoto's thyroiditis is associated with increased arterial wall IMT 
Table 3 Model 1-2: Whole population multiple linear regression

\begin{tabular}{lcccc}
\hline & \multicolumn{2}{c}{ Model 1 } & \multicolumn{2}{c}{ Model 2 } \\
\cline { 2 - 5 } & $\boldsymbol{\beta}$ & $\boldsymbol{P}$ value & $\boldsymbol{\beta}$ & $\boldsymbol{P}$ value \\
\hline Hashimoto & 0.0454 & 0.037 & 0.0451 & $\mathbf{0 . 0 3 9}$ \\
Age & 0.0045 & 0.000 & 0.0045 & $\mathbf{0 . 0 0 0}$ \\
BMI & -0.0017 & 0.372 & - & - \\
Waist circumference & - & - & 0.0006 & 0.518 \\
Glycemia & 0.0019 & 0.064 & 0.0015 & 0.162 \\
Insulinemia & -0.0004 & 0.479 & -0.0008 & 0.224 \\
TSH & 0.0092 & 0.313 & 0.0066 & 0.471 \\
FT3 & 0.0477 & 0.061 & 0.0400 & 0.111 \\
FT4 & 0.0058 & 0.437 & 0.0061 & 0.410 \\
Total cCholesterol & 0.0000 & 0.880 & -0.0001 & 0.832 \\
HDL cholesterol & -0.0012 & 0.194 & -0.0011 & 0.252 \\
Triglycerides & 0.0002 & 0.472 & 0.0002 & 0.415 \\
Hypertension & 0.0319 & 0.138 & 0.0241 & 0.254 \\
\hline
\end{tabular}

[IMT-CCA: dependent variable; Hashimoto, age, BMI, fasting glycemia, fasting insulinemia, TSH/FT3/FT4, total/HDL cholesterol, triglycerides, hypertension: independent variables $\left.\left(R^{2}=0.41, P<0.001\right)\right]$

regardless of thyroid function and well-known cardiovascular risk factors, such as abdominal obesity, hypertension, fasting glycemia, serum insulin and lipid levels. This seems to suggest that auto-immune thyroiditis is in itself a marker of evolution of the atherosclerotic process, particularly in overweight and obese subjects. It seems due to the linkage between the auto-immune process end the endocrinal state consequence to overweight and obesity.

\section{Abbreviations}

IMT: intima-media thickness; IMT-CCA: intima-media thickness of the common carotid artery; BMl: Body mass index; FT3: free triiodothyronine; FT4: free thyroxine; TSH: thyroid-stimulating hormone; Tg-Ab: serum antithyroglobulin; TPO-Ab: anti-thyroid peroxidase antibodies; NCEP: National Cholesterol Education Program; SBP: systolic blood pressure; DBP: diastolic blood pressure

\section{Author details}

${ }^{1}$ Section of Cardiovascular Disease, Department of Emergency and Organ Transplantation, University of Bari, School of Medicine, Bari, Italy. ${ }^{2}$ Section of Internal Medicine, Endocrinology, Andrology and Metabolic Disease, Department of Emergency and Organ Transplantation, University of Bari, School of Medicine, Bari, Italy. ${ }^{3}$ Cardiology Unit- M. Sarcone Hospital, Terlizzi, Bari, Italy.

\section{Authors' contributions}

MMC and GDP conceived and designed the study, analysed and interpreted the data, drafted the article and critically reviewed its intellectual content, and finally approved the version to be submitted for publication. MTP measured and calculated IMT data, reviewed the article's intellectual content, and finally approved the version to be submitted for publication. PS, PC, MI and PG. analysed the data, reviewed the article's intellectual content, and finally approved the version to be submitted for publication. FG contributed towards designing the study, interpreting the endocrinological data, critically reviewing the article's intellectual content, and finally approving the version to be submitted for publication. SF contributed towards designing the study, interpreting the cardiological data, critically reviewing the article's intellectual content, and finally approving the version to be submitted for publication. All authors read and approved the final manuscript.

\section{Competing interests}

The authors declare that they have no competing interests.

Received: 5 January 2010 Accepted: 28 May 2010

Published: 28 May 2010

\section{References}

1. Coppola AR, Ladenson PW: Hypothyroidism and atherosclerosis. J Clin Endocrinol Metab 88:2438-2444.

2. Rodondi N, Bauer DC, Cappola AR, et al: Subclinical Thyroid Dysfunction, Cardiac Function, and the Risk of Heart Failure: The Cardiovascular Health Study. J Am Coll Cardiol 2008, 52:1152-1159.

3. Ripoli A, Pingitore A, Favilli B, Bottoni A, Turchi S, Osman NF, De Marchi D, Lombardi M, L'Abbate A, lervasi G: Does Subclinical Hypothyroidism Affect Cardiac Pump Performance? Evidence From a Magnetic Resonance Imaging Study Journal of the American College of Cardiology. 2005, 45(3):439-45.

4. Bastenie PA, Vanhaelst $L$, Neve P: Coronary artery disease in hypothyroidism: observation in preclinical myxoedema. Lancet 1967, 2:1221-1222

5. Bastenie PA, Vanhaelst L, Bonnyns M, Neve P, Staquet M: Preclinical hypothyroidism: a risk factor for coronary heart disease. Lancet 1971, 1:203-204.

6. Flynn RW, MacDonald TM, Jung RT, Morris AD, Leese GP: Mortality and Vascular Outcomes in Patients Treated for Thyroid Dysfunction. The Journal of Clinical Endocrinology \& Metabolism 2006, 91(6):2159-2164.

7. Taddei S, Caraccio N, Virdis A, Dardano A, Versari D, Ghiadoni L, Ferrannini E, Salvetti A, Monzani F: Low-Grade Systemic Inflammation Causes Endothelial Dysfunction in Patients with Hashimoto's Thyroiditis. The Journal of Clinical Endocrinology \& Metabolism 2006, 91(12):5076-5082.

8. National Institutes of Health, National heart, lung and blood institute Third Report of the National Cholesterol Education Program (NCEP) Expert Panel on Detection, Evaluation, and Treatmentof High Blood Cholesterol in Adults(Adult Treatment Panel III) Final Report. , NIH Publication No. 02-5215 September 2002.

9. Pignoli P, Tremoli E, Poli A, Oreste P, Paoletti R: Intimal plus medial thickness of the arterial wall: a direct measurement with ultrasound imaging. Circulation 1986, 74:1399-1406.

10. O'Leary DH, Polak JF: Intima-media thickness: a tool for atherosclerosis imaging and event prediction. Am J Cardiol 2002, 90:181-211.

11. Ciccone M, De Pergola G, Pannacciulli N, Modugno M, Sciaraffia M, Minenna A, Rizzon P, Giorgino R: Lower insulin sensitivity as an independent risk factor for carotid wall thickening in normotensive nondiabetic non-smoker normal weight and obese premenopausal women. Int J Obesity 2000, 24:825-829.

12. Ciccone M, Pannacciulli N, De Pergola G, Rizzon P, Giorgino F, Giorgino R: Effects of family history of type 2 diabetes on intima-media thickness of the common carotid artery in normal weight, overweight, and obese glucose-tolerant young adults. Diabetes Care 2003, 26:1230-1234.

13. Salonen JT, Salonen R: Ultrasound B-mode imaging in observational studies of atherosclerotic progression. Circulation 1993, 87(suppl II):56-65.

14. Stamatelopoulos KS, Kyrkou K, Chrysochoou E, Karga H, Chatzidou S, Georgiopoulos G, Georgiou S, Xiromeritis K, Papamichael CM, Alevizaki M: Arterial stiffness but not intima-media thickness is increased in euthyroid patients with Hashimoto's thyroiditis: The effect of menopausal status. Thyroid 2009, 19(8):857-62.

15. Naya T, Hosomi N, Ohyama H, Ichihara S-I, Ban CR, Takahashi T, Taminato T, Feng A, Kohno M, Koziol JA: Smoking, Fasting Serum Insulin, and Obesity Are the Predictors of Carotid Atherosclerosis in Relatively Young Subjects Angiology. 2008, 58(6):677-684.

16. Mitsuru Ito, Arishima T, Kudo T, Nishihara E, Ohye H, Kubota S, Fukata S, Amino N, Kuma K, Sasaki I, Hiraiwa T, Hanafusa T, Takamatsu J, Miyauch A: BRIEF REPORT: Effect of Levo-Thyroxine Replacement on Non-HighDensity Lipoprotein Cholesterol in Hypothyroid Patients. The Journal of Clinical Endocrinology \& Metabolism 2007, 92(2):608-611.

17. Monzani F, Caraccio N, Koza 'Kowa' M, Dardano A, Vittone F, Virdis A, Taddei S, Palombo C, Ferrannini E: Effect of Levothyroxine Replacement on Lipid Profile and Intima-Media Thickness in Subclinical Hypothyroidism: A Double-Blind, Placebo-Controlled Study. The Journal of Clinical Endocrinology \& Metabolism 2004, 89(5):2099-2106. 
18. Meyer AA, Kundt G, Lenschow U, Schuff-Werner P, Kienast W: Improvement of Early Vascular Changes and Cardiovascular Risk Factors in Obese Children After a Six-Month Exercise Program. Journal of the American College of Cardiology 2006, 48(9):1865-70.

19. Scuteri A, Najjar SS, Muller DC, Andres R, Hougaku H, Jeffrey Metter E, Lakatta EG: Metabolic Syndrome Amplifies the Age-Associated Increases in Vascular Thickness and Stiffness. Journal of the American College of Cardiology 2004, 43(8):1388-95.

20. Wakabayashi I, Masuda H: Relationships Between Vascular Indexes and Atherosclerotic Risk Factors in Patients With Type 2 Diabetes Mellitus. Angiology 2008, 59(5):567-573.

21. Genoud M, Wietlisbach V, Feihl F, Mermod A, Morin D, Nicod P, Mooser V, Waeber B, Hayoz D, Waeber G: Surrogate Markers for Atherosclerosis in Overweight Subjects With Atherogenic Dyslipidemia. The GEMS Project Angiology 2008, 59(4):484-492.

22. Fernández-Veledo S, Nieto-Vazquez I, de Castro J, Pilar Ramos M, Brüderlein S, Möller P, Lorenzo M: Hyperinsulinemia Induces Insulin Resistance on Glucose and Lipid Metabolism in a Human Adipocytic Cell Line: Paracrine Interaction with Myocytes. The Journal of Clinical Endocrinology \& Metabolism 2008, 93(7):2866-2876.

23. Hong-Kyu Kim, Sung-Kwang Lee, Chan-Jong Suh, Hyo-Joong Yoon, KiYoung Lee, Hye-Young Park, Moon-Ho Kang: Postchallenge hyperglycemia but not hyperinsulinemia is associated with angiographically documented coronary atherosclerosis in Korean subjects. Diabetes research and clinical practice 2003, 59(2):129-136

24. Ishizaka N, Ishizaka Y, Yamakado M, Toda E, Koike K, Nagai R: Association between metabolic syndrome and carotid atherosclerosis in individuals without diabetes based on the oral glucose tolerance test. Atherosclerosis 2009, 204(2):619-23.

25. Neil Thomas G, Ping Chook, Mu Qiao, Huang Xin S, Leong Hok C, Celermajer David S, Kam S: Woo Deleterious Impact of "High Normal" Glucose Levels and Other Metabolic Syndrome Components on Arterial Endothelial Function and Intima-Media Thickness in Apparently Healthy Chinese Subjects. The CATHAY Study Arterioscler Thromb Vasc Biol 2004, 24:739-743.

26. Faeh D, William J, Yerly P, Paccaud F, Bovet P: Diabetes and pre-diabetes are associated with cardiovascular risk factors and carotid/femoral intima-media thickness independently of markers of insulin resistance and adiposity. Cardiovascular Diabetology 2007, 6:32.

27. Pannacciulli N, De Pergola G, Ciccone M, Rizzon P, Giorgino F, Giorgino R: Effect of Family History of Type 2 Diabetes on the Intima-Media Thickness of the Common Carotid Artery in Normal-Weight, Overweight, and Obese Glucose-Tolerant Young Adults. Diabetes care 2003, 26(4):1230-4.

28. Chopra V, Vasisht S, Gulati S, Aggarwal R, Bahl VK, Manchanda SC: Interrelationship between angiographically defined coronary artery disease, plasma insulin levels and lipids in Indian patients. Indian journal of medical sciences 2000, 54(3):81-86.

29. Frostegård J: Atherosclerosis in Patients With Autoimmune Disorders. Arterioscler Thromb Vasc Biol 2005, 25:1776-1785.

30. Qiao JH, Castellani LW, Fishbein MC, Lusis AJ: Immune-complex-mediated vasculitis increases coronary artery lipid accumulation in autoimmuneprone MRL mice. Arterioscler Thromb Vasc Biol 1993, 13:932-943.

\section{Pre-publication history}

The pre-publication history for this paper can be accessed here: http://www.biomedcentral.com/1471-2261/10/22/prepub

doi:10.1186/1471-2261-10-22

Cite this article as: Ciccone et al:: Increased carotid IMT in overweight and obese women affected by Hashimoto's thyroiditis: an adiposity and autoimmune linkage? BMC Cardiovascular Disorders 2010 10:22.

\section{Submit your next manuscript to BioMed Central and take full advantage of:}

- Convenient online submission

- Thorough peer review

- No space constraints or color figure charges

- Immediate publication on acceptance

- Inclusion in PubMed, CAS, Scopus and Google Scholar

- Research which is freely available for redistribution

Submit your manuscript at www.biomedcentral.com/submit
Biomed Central 